\title{
Preterm Lung Exhibits Distinct Spatiotemporal Proteome Expression at Initiation of Lung Injury
}

\author{
Prue M. Pereira-Fantini ${ }^{1,2}$, Boyuan Pang ${ }^{1}$, Sean G. Byars ${ }^{3,4}$, Regina B. Oakley ${ }^{1}$, Elizabeth J. Perkins ${ }^{1}$, \\ Peter A. Dargaville ${ }^{5}$, Peter G. Davis ${ }^{1,6,7}$, Shuai $\mathrm{Nie}^{8}$, Nicholas A. Williamson ${ }^{8}$, Vera Ignjatovic ${ }^{2,9}$, and \\ David G. Tingay ${ }^{1,2,10}$
}

${ }^{1}$ Neonatal Research, and ${ }^{9}$ Haematology Research, Murdoch Children's Research Institute, Parkville, Victoria, Australia; ${ }^{2}$ Department of Paediatrics, ${ }^{3}$ Department of Clinical Pathology, ${ }^{4}$ Melbourne Integrative Genomics, ${ }^{7}$ Department of Obstetrics and Gynaecology, and ${ }^{8}$ Bio21 Institute, University of Melbourne, Parkville, Victoria, Australia; ${ }^{5}$ Menzies Institute for Medical Research, University of Tasmania, Hobart, Tasmania, Australia; ${ }^{6}$ The Royal Women's Hospital, Parkville, Victoria, Australia; and ${ }^{10}$ Department of Neonatology, Royal Children's Hospital, Parkville, Victoria, Australia

ORCID ID: 0000-0003-1522-4691 (D.G.T.).

\begin{abstract}
The development of regional lung injury in the preterm lung is not well understood. This study aimed to characterize time-dependent and regionally specific injury patterns associated with early ventilation of the preterm lung using a mass spectrometry-based proteomic approach. Preterm lambs delivered at 124-127 days gestation received 15 or 90 minutes of mechanical ventilation (positive end-expiratory pressure $=8 \mathrm{~cm} \mathrm{H}_{2} \mathrm{O}, \mathrm{VT}=6-8 \mathrm{ml} / \mathrm{kg}$ ) and were compared with unventilated control lambs. At study completion, lung tissue was taken from standardized nondependent and dependent regions, and assessed for lung injury via histology, quantitative PCR, and proteomic analysis using Orbitrap-mass spectrometry. Ingenuity pathway analysis software was used to identify temporal and region-specific enrichments in pathways and functions. Apoptotic cell numbers were ninefold higher in nondependent lung at 15 and 90 minutes compared with controls,
\end{abstract}

whereas proliferative cells were increased fourfold in the dependent lung at 90 minutes. The relative gene expression of lung injury markers was increased at 90 minutes in nondependent lung and unchanged in gravity-dependent lung. Within the proteome, the number of differentially expressed proteins was fourfold higher in the nondependent lung than the dependent lung. The number of differential proteins increased over time in both lung regions. A total of $95 \%$ of enriched canonical pathways and $94 \%$ of enriched cellular and molecular functions were identified only in nondependent lung tissue from the 90-minute ventilation group. In conclusion, complex injury pathways are initiated within the preterm lung after 15 minutes of ventilation and amplified by continuing ventilation. Injury development is region specific, with greater alterations within the proteome of nondependent lung.

Keywords: preterm; proteomics; lung injury; mechanical ventilation

(Received in original form March 12, 2019; accepted in final form April 15, 2019)

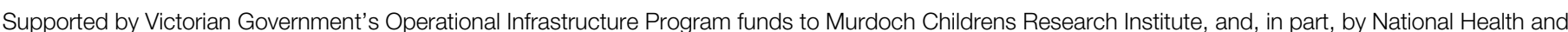

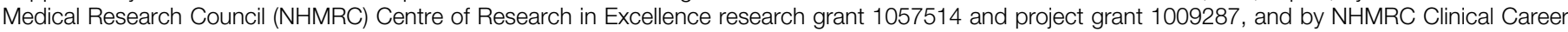
Development Fellowship grants 1053889 and 1123859 (D.G.T.).

Author Contributions: P.M.P.-F._-study conception and design, analysis and interpretation of data, drafting of the manuscript, and statistical analysis;

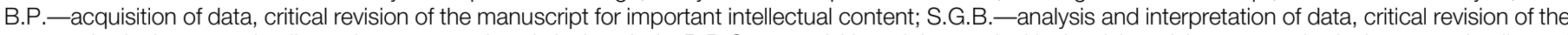

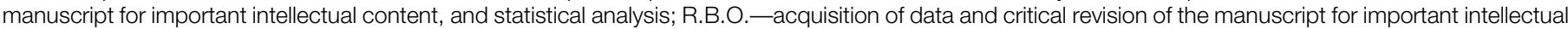

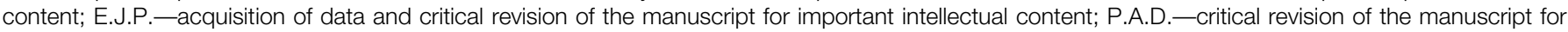

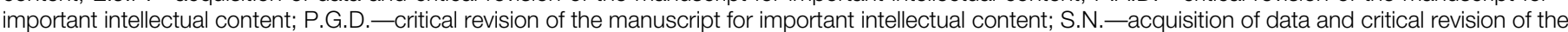

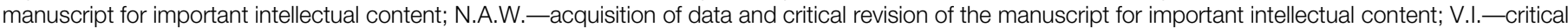
revision of the manuscript for important intellectual content; D.G.T.-study conception and design and critical revision of the manuscript for important intellectual content, obtained funding, and study supervision.

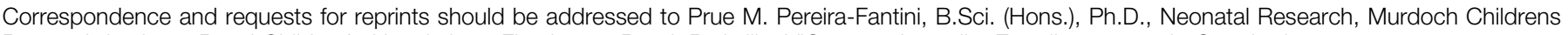
Research Institute, Royal Children's Hospital, 55 Flemington Road, Parkville, VIC 3052, Australia. E-mail: prue.pereira@mcri.edu.au.

This article has a data supplement, which is accessible from this issue's table of contents at www.atsjournals.org.

Am J Respir Cell Mol Biol Vol 61, Iss 5, pp 631-642, Nov 2019

Copyright (C) 2019 by the American Thoracic Society

Originally Published in Press as DOI: 10.1165/rcmb.2019-0084OC on April 17, 2019

Internet address: www.atsjournals.org 
In preterm infants, the lung is structurally immature, surfactant deficient, and prone to collapse. Consequently, preterm infants often require respiratory support, either via mechanical ventilation or noninvasive respiratory support to ensure survival. However, even brief periods of mechanical ventilation applied to the structurally fragile preterm lung can initiate inflammation and injury (1), and may influence the effectiveness of subsequent therapies, such as surfactant (2-4). Furthermore, ventilator-induced lung injury (VILI) rarely resolves while mechanical ventilation is continuing (5).

Underlying VILI development in the preterm lung is a complex interplay between mechanical traumas, such as barotrauma, volutrauma, or atelectotrauma and biological injury responses known collectively as biotrauma. In preterm infants, the structural immaturity and surfactant-deficient state of the lung can result in delivery of excessive VTs to those lung units first engaged in aeration, setting in process a pattern of inhomogeneous ventilation (6) and thereby exposing the lung to injury from over-distension in some regions and atelectasis and shear forces in others (7). In adult experimental models, inhomogeneous ventilation causes regional lung strain and leads to the development of regionally specific inflammatory responses (8). Furthermore, in adult humans, the risk of developing VILI is higher with increased ventilation inhomogeneity due to the induction of regional stress patterns (9). This mechanism of injury is very likely at play in the preterm infant; however, experimental studies of the immature lung have predominantly chosen a whole-lung, single-time point approach, thereby preventing documentation of regional injury development. Proteomics has the capacity to facilitate mapping, at a cellular level, the time-dependent, regional injury response to ventilation of the preterm lung.

In this study, we aimed to characterize the temporal proteome response in the nondependent and gravity-dependent lung regions from birth. Using the lamb model of preterm birth, we compared alterations between nondependent and gravitydependent lung tissue after either 15 minutes or 90 minutes of ventilation. We initially provide histological evidence of temporally evolving morphological patterns with regionally specific induction of apoptosis and proliferation. Alterations in gene expression of lung injury markers evolved with time spent on ventilation, but were confined to the nondependent lung. Finally, we demonstrate that proteome complexity develops over time and in a regional specific manner, with the greatest magnitude of change observed within the nondependent lung after 90 minutes of ventilation.

\section{Methods}

A detailed description of the methods is provided in the data supplement. The study was performed at the animal research facility of the Murdoch Children's Research Institute and approved by our Animal Ethics committee.

\section{Mechanical Ventilation Strategy}

Border-Leicester/Suffolk lambs (124$127 \mathrm{~d}$ gestation) exposed to antenatal corticosteroids were delivered via caesarean section under general anesthesia. While on placental support, lambs were instrumented and intubated, lung fluid was passively drained, and a circumferential array of electrodes positioned for electrical impedance tomography (EIT; Swisstom Pioneer system; Swisstom) as previously described (3).

To ensure optimal detection of the acute injury response, two model variations were studied: a placental support model (15-min ventilation study group; $n=7$ ) and a placenta-independent model (90-min ventilation study group; $n=10$ ). The placental support model enabled evaluation of a brief period of standardized positivepressure ventilation (PPV) while limiting the confounding effect of oxygen exposure (5). However, it was not sustainable for longer periods of ventilation, and does not replicate the usual clinical course after preterm birth. Therefore, we also studied tissue from a placenta-independent model in which preterm lambs were maintained solely with mechanical ventilation for 90 minutes. All lambs received PPV in volume-targeted mode (SLE5000; SLE Ltd.) at positive endexpiratory pressure (PEEP) of $8 \mathrm{~cm} \mathrm{H}_{2} \mathrm{O}$ and initial set $\mathrm{VT}_{\mathrm{T}}$ of $7 \mathrm{ml} / \mathrm{kg}$, or were assigned to a third no-ventilation control group. Arterial blood gas analyses were performed at 5, 10, and 15 minutes, and then 15 minutely.

Lambs receiving 15 minutes of ventilation remained on placental support throughout, with the endotracheal tube clamped at PEEP at 15 minutes. Lambs were then maintained solely on placental support for a further 30 minutes to allow for the expression of lung injury markers as per the method of Hillman and coworkers (10). Lambs assigned to the 90-minute ventilation group were maintained on PPV for the entire study period, independent of placental support. Fraction of inspired oxygen was initially 0.3 in the placentaindependent (90-min) group and the ewes in the 15-minute group, and altered to maintain oxygen saturation as measured by pulse oximetry $\left(\mathrm{Sp}_{\mathrm{O}_{2}}\right)$ 88-95\%. VT and ventilator rate were adjusted as required to maintain $\mathrm{Pa}_{\mathrm{CO}_{2}}$ in the range of 45-60 mm Hg. All lambs, including an additional group of unventilated controls (0-min group) received a lethal dose of pentobarbitone at study completion.

\section{Physiological Measurements}

Regional aeration and ventilation (EIT), airway pressure, $\mathrm{V}_{\mathrm{T}}$, and dynamic compliance (Cdyn) were measured continuously for the first 15 minutes and then for 2 minutes before each arterial blood gas analysis, as detailed previously $(3,11)$.

\section{Sample Collection}

At study completion, lung tissue was taken from standardized nondependent and gravity-dependent sites within the right upper lobe for histology and right lower lobe for gene and protein analysis.

\section{Lung Histology}

Histological examination of sections stained with hematoxylin and eosin was performed on composite micrographs (Olympus BX51 slide scanner; Olympus). Immunohistochemistry was used to detect apoptotic cells (cleaved caspase-3; R\&D Systems) and proliferative cells (Ki-67; Abcam). All postimage analysis was performed using the ImageJ software suite (National Institutes of Health; available from: https://imagej.nih.gov/nih-image/).

\section{RNA Preparation and Quantitative PCR}

RNA was extracted from lung tissue using TRIzol, and $0.1 \mu \mathrm{g}$ RNA was reverse transcribed into cDNA. All quantitative RT-PCR reactions were performed in triplicate on the Light-Cycler 480 System (Roche). The $2^{-\Delta \Delta \mathrm{Ct}}$ method (12) was used to calculate relative changes in gene expression, determined from quantitative RT-PCR experiments using RPS29 as a housekeeping gene and relative to the 0 -minute group (13). Primer sequences are detailed in Table E1 in the data supplement. 


\section{Determination of Protein Composition via Orbitrap Mass Spectrometry}

Protein extraction and digestion. Protein extractions were performed on the same day using the same batch of reagents. Tryptic digestion and desalting were performed before samples were reconstituted to $50 \mu \mathrm{g} / 100 \mu \mathrm{l}$ in mass spectrometry (MS)-loading buffer.

Liquid chromatography and tandem MS analysis. Peptide samples $(1 \mu \mathrm{l})$ at $500 \mathrm{ng} / \mu \mathrm{l}$ were analyzed with liquid chromatography and tandem MS using an Orbitrap Elite mass spectrometer (Thermo Fisher Scientific) coupled to an Ultimate 3000 UHPLC (Thermo Fisher Scientific). To avoid batch effects, all samples were run in tight temporal sequence with no other samples analyzed in between the study samples.

Peptide identification. Orbitrap elite raw files were viewed in Xcalibur software (Thermo Fisher Scientific) and abnormal ion content chromatograms excluded from further analysis. MaxQuant software (Ver. 1.5.3.30; Max Planck Institute of Biochemistry) was used to identify proteins using the Uniprot Ovies Aries database. Proteins with a false discovery rate of $1 \%$ or less, and with a minimum detection rate of five replicates per group, were considered for further analysis.

Ingenuity pathway analysis. Enriched pathways and functions associated with the proteome data sets were identified using ingenuity pathway analysis (IPA) software (Qiagen) with lung-specific filters enabled as detailed in the data supplement. As sheep proteins are not represented in IPA, only proteins exhibiting $65 \%$ or greater homology to human protein sequences after assessment by National Center for Biotechnology Information Basic Local Alignment Search Tool (BLAST) were included in the analysis.

\section{Statistical Analysis}

EIT, histology, and gene expression. Data were tested for normality and analyzed in PRISM 6 (GraphPad Software, Inc.). A $P$ value less than 0.05 was considered significant, and time and region used as factors for two-way ANOVA.

Proteome analysis. Protein abundance data at the individual protein level obtained from either nondependent or gravity-dependent lung tissue samples exposed to either no ventilation, 15 or 90 minutes of ventilation was tested for normality, and one-way ANOVA testing performed. Holm-Sidak (parametric data) or Dunn's (nonparametric data) multiple comparison posttesting was performed and proteins exhibiting $P$ values of less than 0.05 in protein abundance in 0 -minute versus 15 -minute ventilation or 0 -minute versus 90 -minute ventilation were considered differentially expressed between the groups. To assess whether there were time-dependent or regionspecific differences in the composition of the proteome, partial least squaresdiscriminant analysis was performed in the $\mathrm{R}$ package MixOmics (version 3.1.1).

\section{Results}

\section{Ventilation Outcomes Are Largely Comparable between the Placental Support and Placenta-Independent Models}

A total of 24 lambs delivered from 20 ewes were studied. No ewes had evidence of sepsis or chorioamnionitis. Study groups were comparable for gestational age, weight, and parity, but there were more females in the unventilated control group and first borns in the 90-minute ventilation study group (Table E2). There was no difference in delivery of $\mathrm{VT}_{\mathrm{T}}$ or PEEP between the placental support model (15-min study group) and the placentaindependent model (90-min study group; Figures 1A and 1B); however, peak inspiratory pressure was slightly elevated in the placental support group at 15 minutes (Figure 1C). Cdyn was comparable between the two study groups (Figure 1D). Among measures of gas exchange, $\mathrm{Sp}_{\mathrm{O}_{2}}$ (Figure 1E) was comparable between the models; however, the alveolar- arterial oxygen difference was higher at 15 minutes, and $\mathrm{Pa}_{\mathrm{CO}_{2}}$ higher at 5 and 15 minutes in the placentaindependent group (Figures $1 F$ and $1 G$ ). In both groups, aeration favored the nondependent region at 15 minutes, although the response at 5 minutes was variable (Figure $1 \mathrm{H}$ ). The spatial distribution of VT was similar to aeration during the first 15 minutes of life. It was initially greater in the nondependent lung at 5 minutes (both groups), becoming more uniform only after 15 minutes of PPV (Figure 1I).

\section{Morphological Evidence of Time- and Region-Specific Patterns of Preterm Lung Injury}

Micrographs representing temporal alterations in morphology are shown in Figure 2A (nondependent lung tissue) and Figure 2B (dependent lung tissue). Morphometric analysis of alveolar units demonstrated a decrease in the number of alveoli per field of view in dependent lung tissue (Figure 2C), and an increase in the average alveolar size (Figure 2D) and alveolar size variance (Figure 2E) in both nondependent and gravity-dependent lung with more prolonged ventilation. Among morphological markers of injury and repair, the number of detached epithelial cells within alveoli was similarly increased approximately threefold after either 15 or 90 minutes of ventilation in both nondependent and dependent lung tissue compared with unventilated controls (Figure 2F). The proportion of apoptotic cells in the gravity-dependent lung was comparable between ventilated and unventilated lambs. By contrast, the nondependent lung exhibited a ninefold increase in the proportion of apoptotic cells at both 15 and 90 minutes of ventilation when compared with unventilated controls (Figure 2G). Conversely, although the proportion of proliferative cells was unchanged in the nondependent lung, in the gravity-dependent lung the proportion of proliferative cells increased over time, with a fourfold increase observed in the dependent lung at 90 minutes of ventilation (Figure $2 \mathrm{H}$ ).

\section{Molecular Evidence of Time- and Region-Specific Patterns of Preterm Lung Injury}

All six genes exhibited increased expression in nondependent lung tissue when compared with gravity-dependent lung tissue. The relative gene expression of IL1BI, IL6, IL8, $C T G F$ (connective tissue growth factor), and CYR61 (cysteine-rich angiogenic inducer 61) was increased at 90 minutes of ventilation in nondependent lung tissue when compared with region-matched unventilated controls and time-matched dependent lung expression (Figures 3A-3E). EGR1 (early growth response-1) gene expression was increased from 15 minutes of ventilation in nondependent lung when compared with unventilated controls (Figure $3 \mathrm{~F}$ ). The dependent lung gene expression of all six genes remained unchanged throughout the ventilation period. 
A

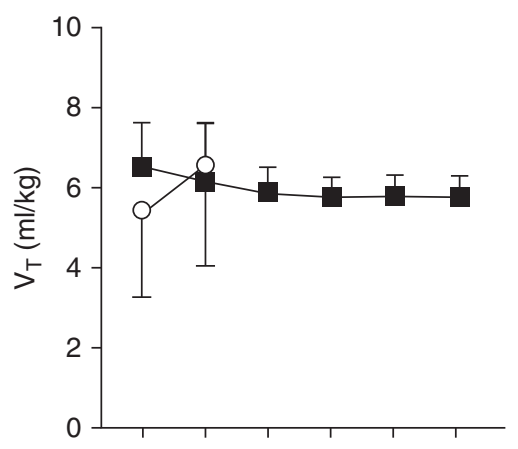

D

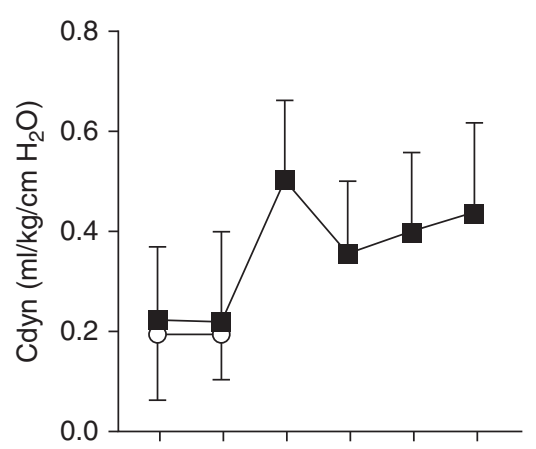

G

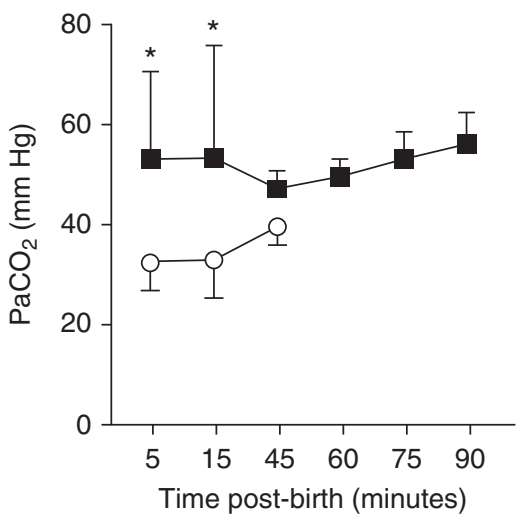

B

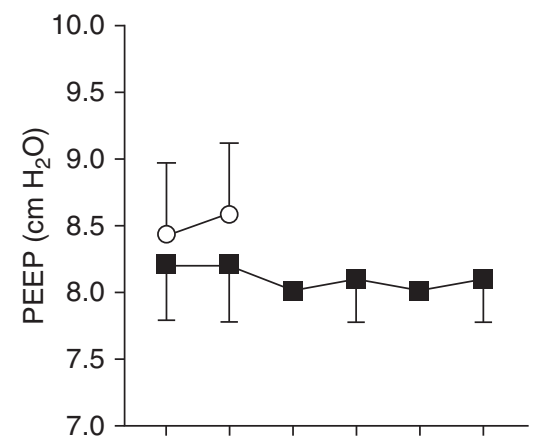

E

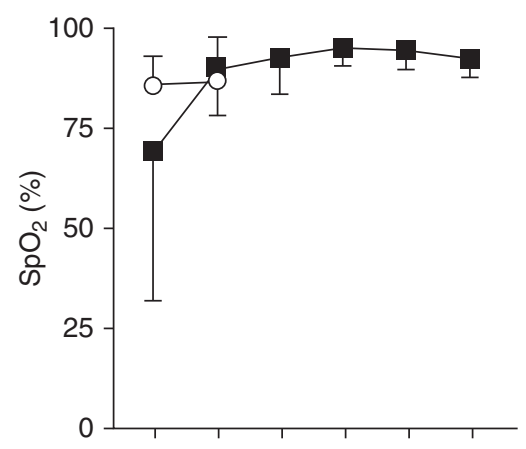

H

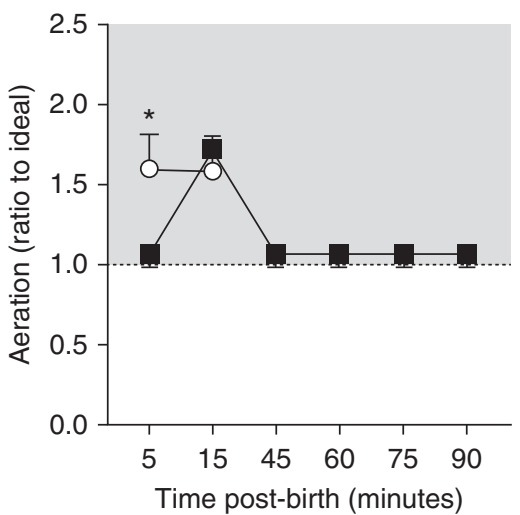

C

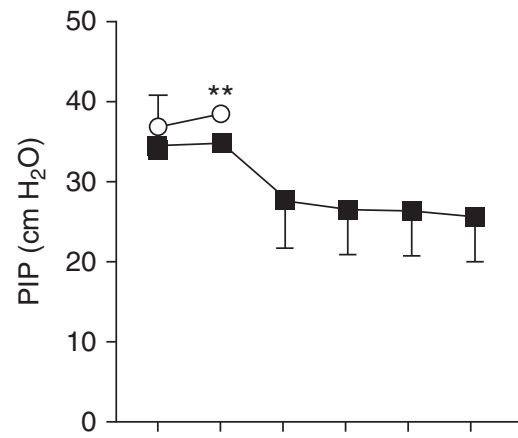

F

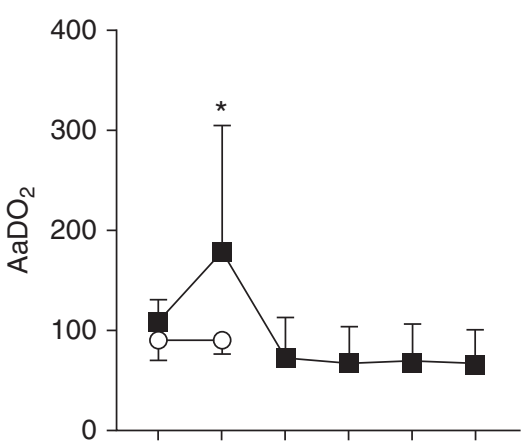

I

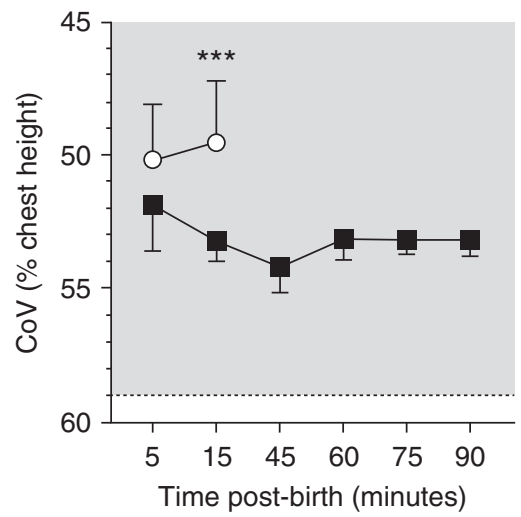

Figure 1. Ventilation and gas exchange parameters for the 15-minute (placental support model) and 90-minute (placenta-independent model) study groups. (A) Tidal ventilation $(\mathrm{V}),(B)$ positive end-expiratory pressure (PEEP), $(C)$ peak inspiratory pressure $(P I P),(D)$ dynamic compliance $(C d y n),(E)$ peripheral oxygen saturation as measured by pulse oximetry $\left(\mathrm{Sp}_{\mathrm{O}_{2}}\right),(F)$ alveolar-arterial oxygen difference $\left(\mathrm{AaDO}_{2}\right),(G)$ arterial carbon dioxide tension/pressure $\left(\mathrm{Pa}_{\mathrm{CO}_{2}}\right),(H)$ regional distribution of aeration, and ( $($ ) tidal ventilation (CoV). Placental support model (open circle) and placenta-independent model (solid squares). Aeration expressed as a ratio to ideal aeration for the anatomical shape of the chest (7), with a value of 1.0 representing homogenous aeration, and greater than 1.0 representing relatively more aeration in the nondependent hemithorax compared with dependent. $V_{T}$ is expressed as the geometric center of gravity-dependent ventilation (CoV), with a value of $59 \%$ representing homogenous ventilation in the preterm lamb (3). The gray squares depict distribution of aeration or ventilation toward the nondependent lung. All data are mean \pm SD. ${ }^{\star} P<0.05,{ }^{\star \star} P<0.01$, and ${ }^{* \star \star} P<0.001$ (one-way ANOVA).

\section{Orbitrap-MS Identified Regional and Time-Specific Alterations in the Lung Proteome}

Using Orbitrap-MS, we identified 1,813 and 1,815 protein group reads with a false discovery rate of less than $1 \%$ in nondependent and dependent lung, respectively. Details of postidentification filtering are presented in Figure 4A, and a complete list of differential proteins provided in Tables E3 and E4. Supervised partial least squares-discriminant analysis displayed minor overlap between the 15and 90-minute ventilation time points in both nondependent and dependent lung tissue, with clearer separation between ventilated and unventilated proteome observed within the dependent lung (Figure 4B). Similar to our earlier histological and molecular observation, a greater number of differentially expressed 
A
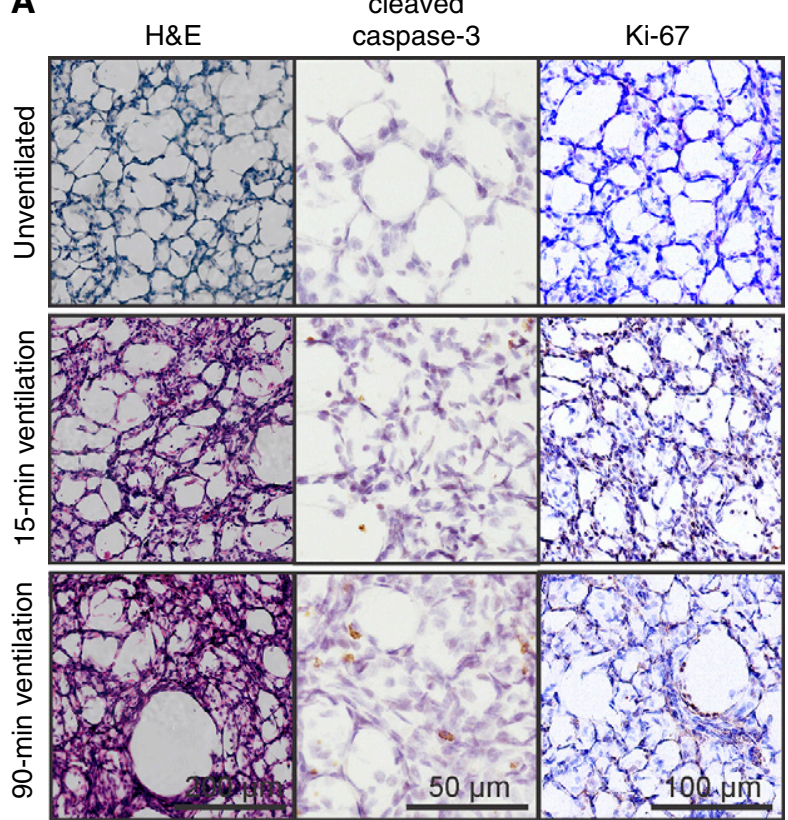

B cleaved

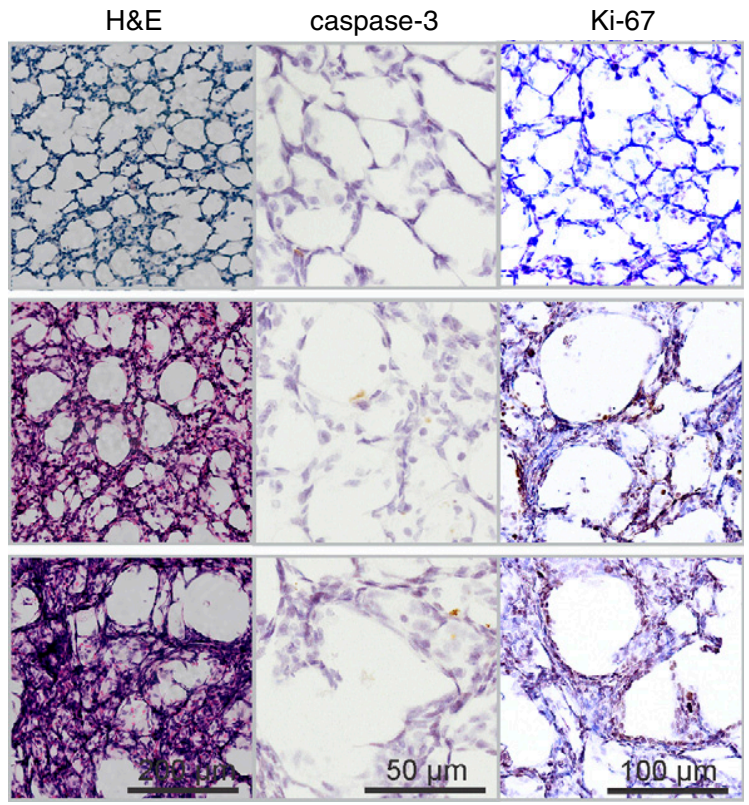

C

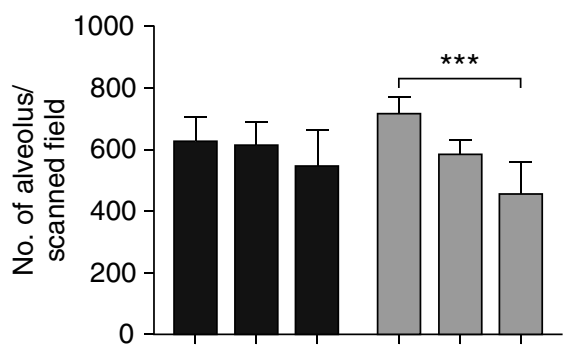

$\mathbf{F}$

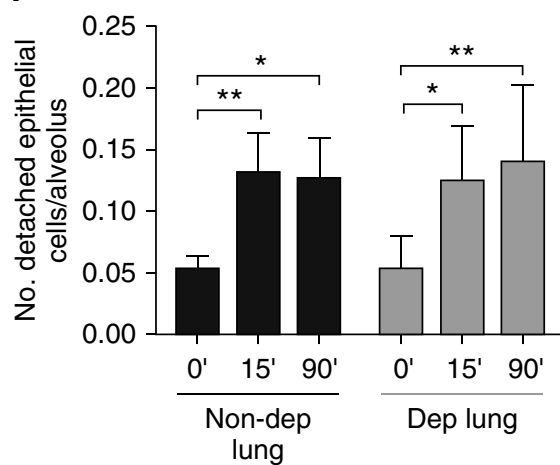

D

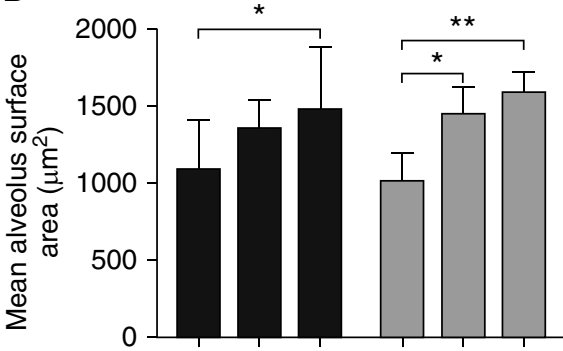

G

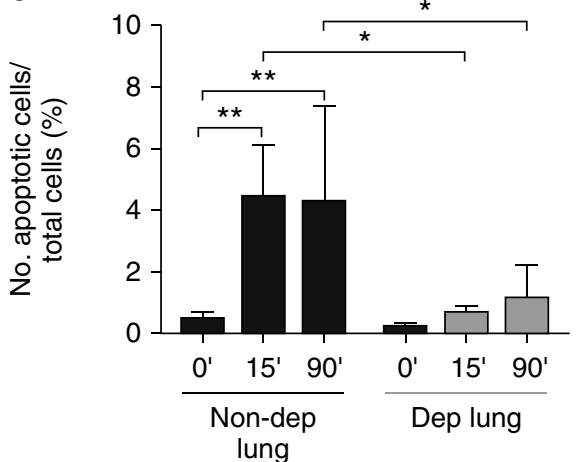

E

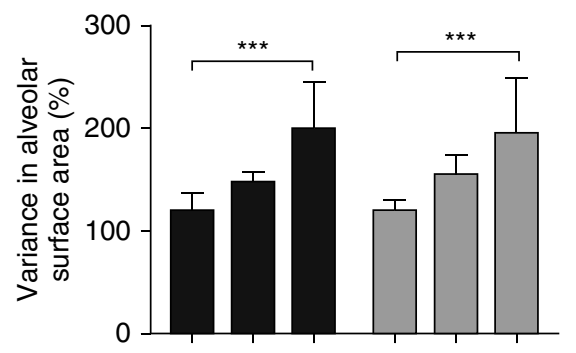

H

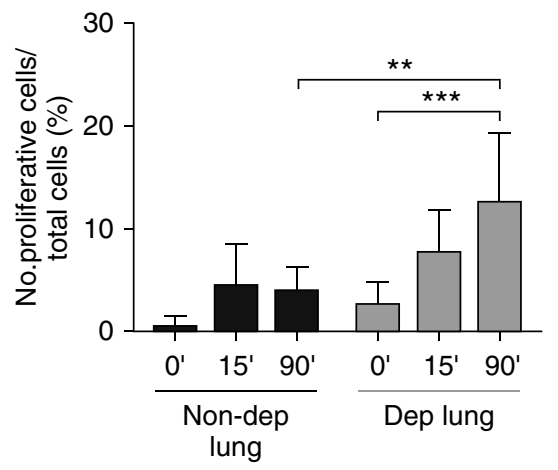

Figure 2. Temporal alterations in regional morphology. (A) Representative micrographs of nondependent lung tissue (Non-dep lung) and (B) dependent lung tissue (Dep lung) from unventilated lambs $\left(0^{\prime}\right)$ and lambs ventilated for either 15 minutes $\left(15^{\prime}\right)$ or 90 minutes $\left(90^{\prime}\right)$. Tissue was stained with hematoxylin and eosin (H\&E) for general morphological assessments, and immunohistochemistry used to detect apoptotic cells (anti-cleaved caspase 3) or proliferative cells (anti-Ki67). Scale bars: $200 \mu \mathrm{m}, 50 \mu \mathrm{m}$, and $100 \mu \mathrm{m}$. (C) Image assessment included quantification of the number of alveoli, (D) mean alveolar size, $(E)$ coefficient of variance in alveolar size, $(F)$ number of detached epithelial cells/alveolus, $(G)$ proportion of apoptotic cells, and $(H)$ proportion of proliferative cells. Data represent mean \pm SD. ${ }^{\star} P<0.05$, ${ }^{\star \star} P<0.01$, and ${ }^{\star \star \star} P<0.001$ (two-way ANOVA).

proteins was observed in nondependent lung tissue compared with dependent lung tissue (158 vs. 41 ), with the number of differentially expressed proteins increased over time in both lung regions (Figure $4 \mathrm{C}$ ).
Volcano plots were used to visualize patterns of differential expression between the groups (Figure 4D). At 15 minutes of ventilation, plots derived from nondependent lung tissue contained more significant proteins with increased expression, as opposed to gravitydependent tissue in which more significant proteins exhibited decreased expression. Increasing and decreasing protein 

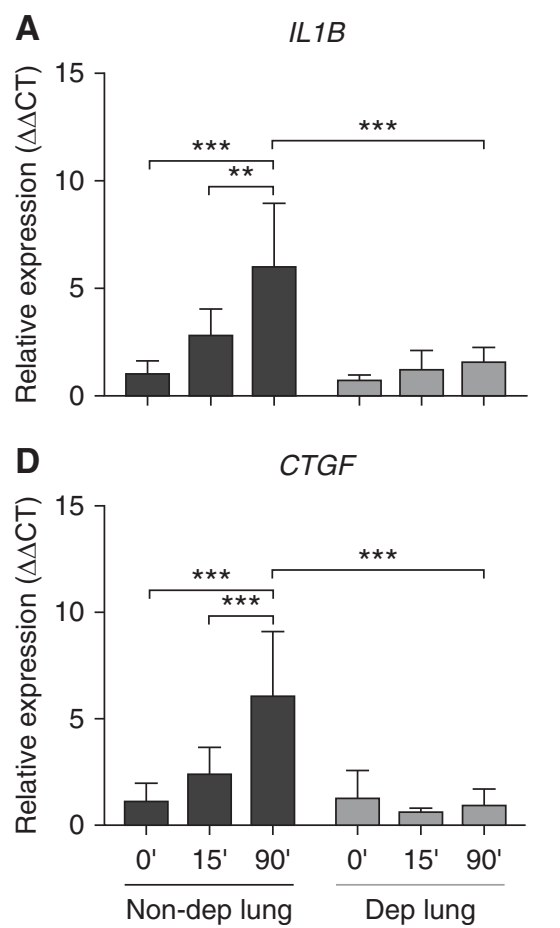

B

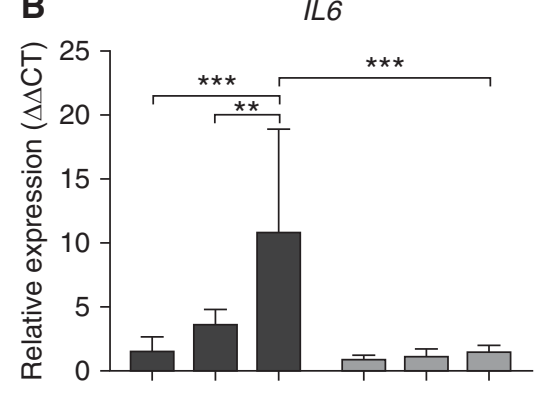

\section{$\mathrm{E}$}

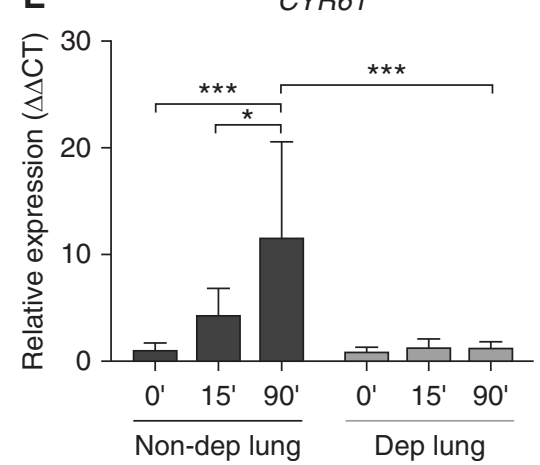

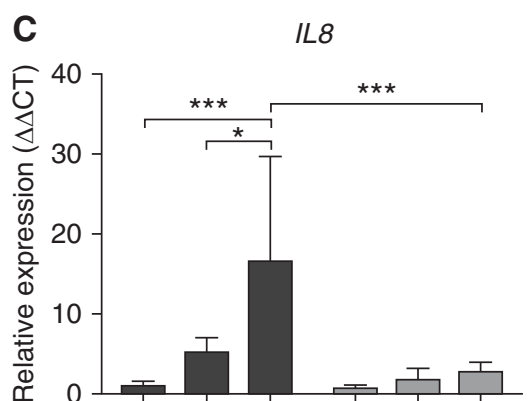

F

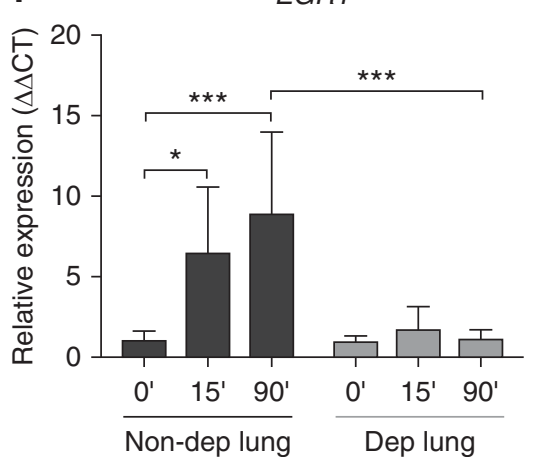

Figure 3. Gene expression of lung injury markers. $(A) I L 1 B,(B) I L 6,(C) I L 8,(D) C T G F$, (E) CYR61, and (F) EGR1 relative gene expression in Non-dep lung (black bar) and Dep lung (gray bar) lung tissue after $0\left(0^{\prime}\right), 15\left(15^{\prime}\right)$, or 90 minutes $\left(90^{\prime}\right)$ of ventilation. Data represent mean $\pm S D$. ${ }^{\star} P<0.05$, ${ }^{\star \star} P<0.01$, and ${ }^{* \star \star} P<0.001$ (two-way ANOVA). CTGF = connective tissue growth factor; CYR61 = cysteine-rich angiogenic inducer 61; EGR1 = early growth response 1.

expression were seen with equal frequency in nondependent and gravity-dependent lung tissue at 90 minutes of ventilation. The cellular location distribution of differentially expressed proteins was comparable among the groups with the exclusion of 15-minute, gravity-dependent lung in which plasma membrane proteins were not differentially expressed (Figure $4 \mathrm{E})$. Protein function increased in diversity with longer ventilation duration in both the nondependent lung (5 vs. 10 identified protein types at 15 and $90 \mathrm{~min}$, respectively) and the dependent lung ( 2 vs. 5 ; Figure $4 \mathrm{~F}$ ).

\section{IPA Identified Time- and Region- Specific Enrichments in Canonical Pathways and Cellular and Molecular Functions}

To facilitate the interpretation of results, only enriched canonical pathways and cellular functions with three or more differentially expressed proteins are reported, with full results detailed in Tables E5 and E6, respectively. A total of 95\% of canonical pathways containing three or more differentially expressed proteins were enriched exclusively in the nondependent lung at 90 minutes of ventilation excluding eukaryotic initiation factor (EIF) 2 signaling, which was enriched at both 15 and 90 minutes of ventilation in the nondependent lung and oxidative phosphorylation and mitochondrial dysfunction pathways, which were enriched in both the nondependent and gravity-dependent lung regions at 90 minutes (Figure 5A). The 59 canonical pathways assigned to 15 pathway classifiers were enriched in the nondependent lung at 90 minutes, including a diverse range of signaling pathways and cellular processes (Figure 5B). Among the top 20 significant pathways identified by IPA (Figure 5C), EIF2 signaling was ranked as the most significant pathway, followed by the NRF2-mediated oxidative stress response with the most represented pathway categories being intracellular and second messenger signaling (EIF2 signaling, regulation of eIF4 and p70S6K signaling, phosphatidylinositol-3/AKT signaling, and integrin signaling), and retinoid $\mathrm{X}$ receptor (RXR) signaling peroxisome proliferatoractivated receptor (PPAR), liver $\mathrm{X}$ receptor (LXR)/RXR, farnesoid $\mathrm{X}$ receptor (FXR)/RXR and PPAR $\alpha / R X R \alpha$ signaling pathways).
Among cellular and molecular functional enrichments, $95 \%$ of enrichments were identified in nondependent lung tissue, predominantly at 90 minutes of ventilation (Figure 6A). Nondependent lung enrichments common to both time points included cell-to-cell signaling and interaction, small-molecule biochemistry, and cellular growth and proliferation (Figure 6B). A single commonality, enrichment of functions associated with cellular development, was identified in nondependent and dependent lung exposed to 90 minutes of ventilation (Figure 6C). A total of 15 cellular and molecular functional enrichments were specific to nondependent lung tissue at 90 minutes of ventilation, including metabolic enrichments, cellular enrichments, molecular enrichments, and indicators of injury (Figure 6D).

We concluded our studies by using the cell type identifier assigned by IPA to each function descriptor to map the cell types associated with three enriched cellular functions within the nondependent lung after 90 minutes of ventilation. Enrichments in "cell-to-cell signaling 
A

\begin{tabular}{|c|c|}
\hline Non-dependent lung & Dependent lung \\
\hline $\begin{array}{l}1,890 \text { protein groups } \\
\text { (initial identification) }\end{array}$ & $\begin{array}{l}1,890 \text { protein groups } \\
\text { (initial identification) }\end{array}$ \\
\hline$\downarrow$ & $\downarrow$ \\
\hline $\begin{array}{l}1,813 \text { protein group reads } \\
(\text { FDR } \leq 1 \%)\end{array}$ & $\begin{array}{c}\mathbf{1 , 8 1 5} \text { protein group reads } \\
(\text { FDR } \leq 1 \%)\end{array}$ \\
\hline$\downarrow$ & $\downarrow$ \\
\hline $\begin{array}{c}1,181 \text { protein groups } \\
(<5 \text { reading/group })\end{array}$ & $\begin{array}{c}1,163 \text { protein groups } \\
(<5 \text { reading/group })\end{array}$ \\
\hline$\downarrow$ & $\downarrow$ \\
\hline $\begin{array}{c}\mathbf{1 , 1 6 2} \text { protein groups } \\
\text { (human homology }>65 \% \text { ) }\end{array}$ & $\begin{array}{c}1,142 \text { protein groups } \\
\text { (human homology }>65 \% \text { ) }\end{array}$ \\
\hline$\nabla$ & $\nabla$ \\
\hline $\begin{array}{l}260 \text { protein groups } \\
\text { (ANOVA; } P<0.05 \text { ) }\end{array}$ & $\begin{array}{l}53 \text { protein groups } \\
\text { (ANOVA; } P<0.05 \text { ) }\end{array}$ \\
\hline$\downarrow$ & $\downarrow$ \\
\hline $\begin{array}{c}158 \text { differential proteins } \\
(P<0.05 \text { vs. } 0 \text {-min })\end{array}$ & $\begin{array}{l}41 \text { differential proteins } \\
(P<0.05 \text { vs. 0-min })\end{array}$ \\
\hline$\downarrow$ & $\downarrow$ \\
\hline $\begin{array}{c}154 \text { proteins analyzed } \\
\text { via IPA }\end{array}$ & $\begin{array}{c}36 \text { proteins analyzed } \\
\text { via IPA }\end{array}$ \\
\hline
\end{tabular}

B

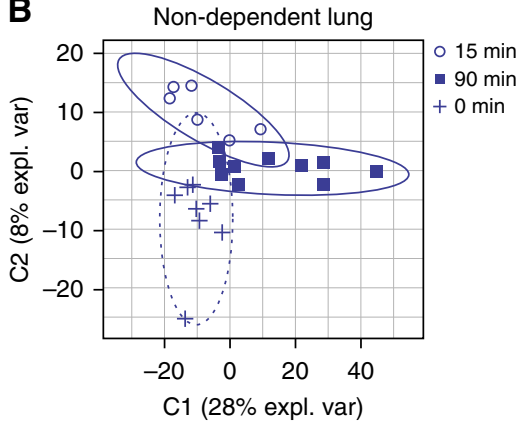

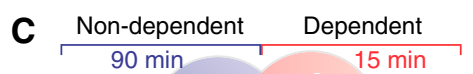

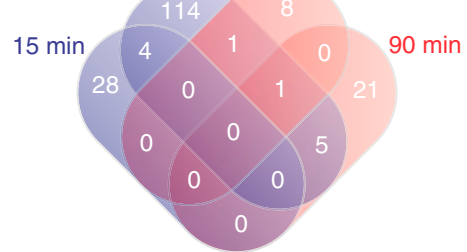

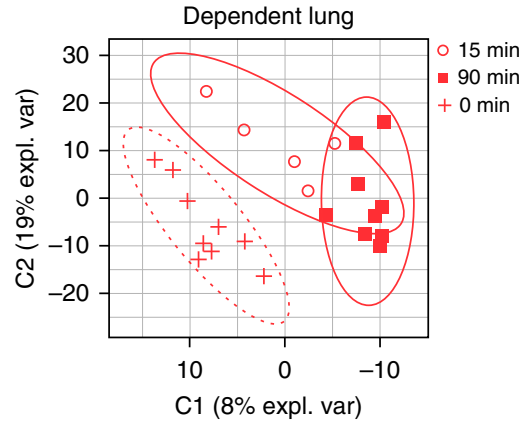

C1 (8\% expl. var)

D
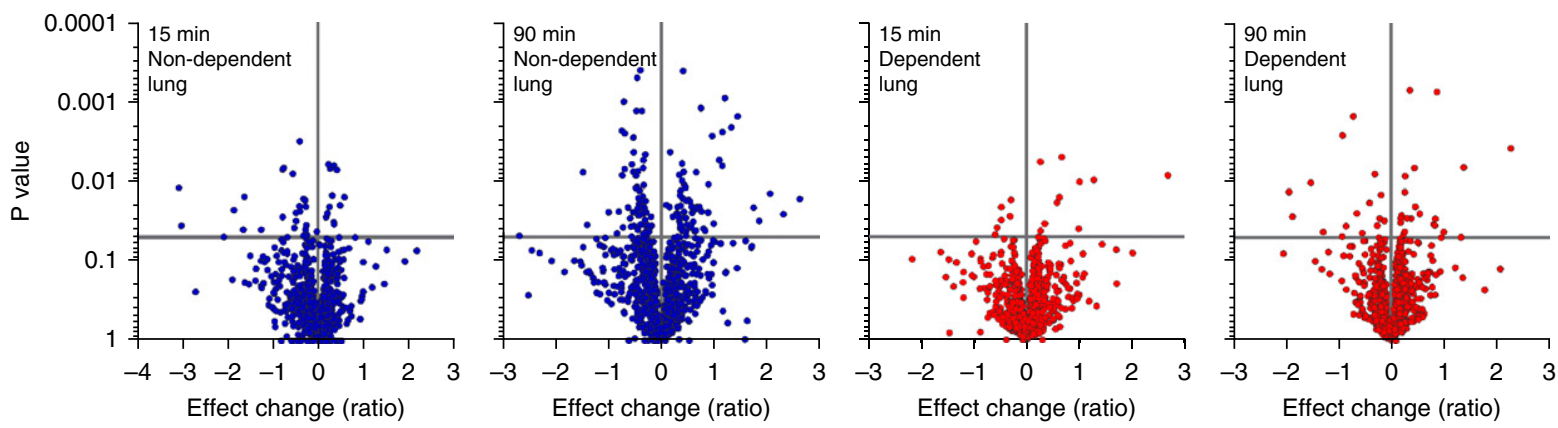

E
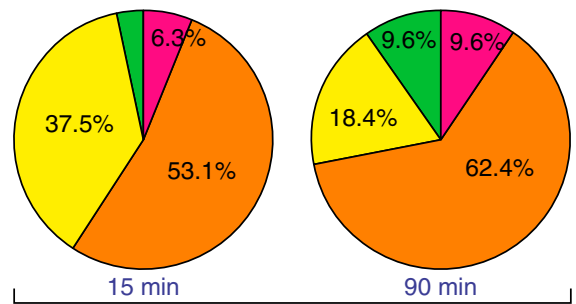

Non-dependent lung
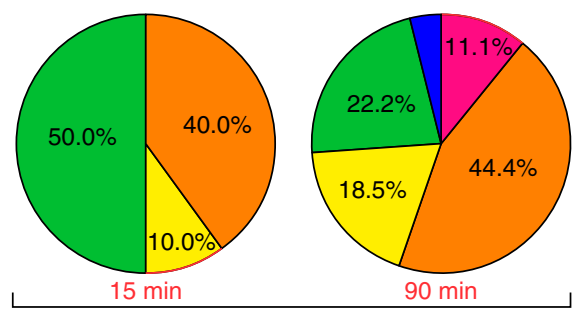

Plasma membrane

$\square$ Cytoplasm

$\square$ Nucleus

Extracellular space

$\square$ Other

Dependent lung
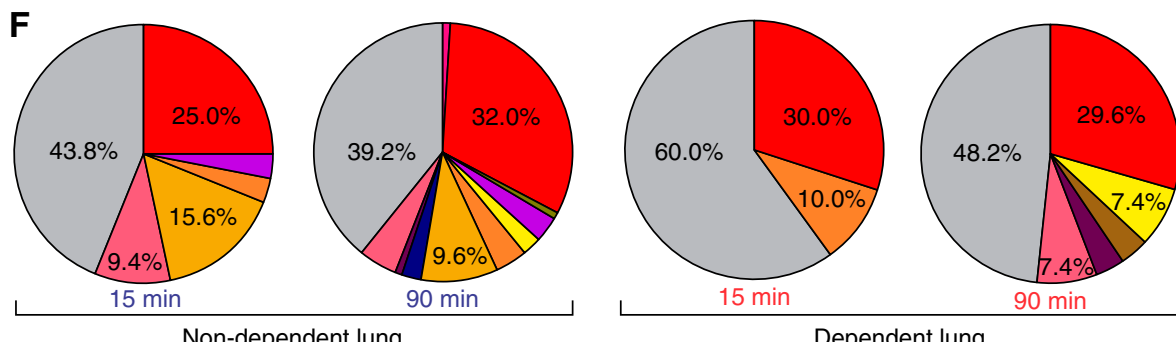

Cytokine

$\square$ Enzyme

$\square$ Growth factor

$\square$ Ion channel

$\square$ Kinase

$\square$ Peptidase

$\square$ Transcription regulator

Translation regulator

Transmembrane receptor

Transmemb
$\square$ Transporter

$\square$ Other

Figure 4. Results from Orbitrap-mass spectrometry analysis of nondependent and dependent lung tissue. (A) Flowchart depiction of the analysis workflow. (B) Partial least squares-discriminant analysis of the proteome data from nondependent and dependent lung tissue. (C) Venn diagram and $(D)$ volcano plot of the differentially expressed proteins in the nondependent and dependent lung after either 15 or 90 minutes of ventilation, relative to the region-matched unventilated control. $(E)$ Location of differentially expressed protein expression within the cell, and $(F)$ assigned functions of observed differentially expressed proteins. Expl. var = explanatory variable; FDR = false discovery rate; IPA = ingenuity pathway analysis. 
A

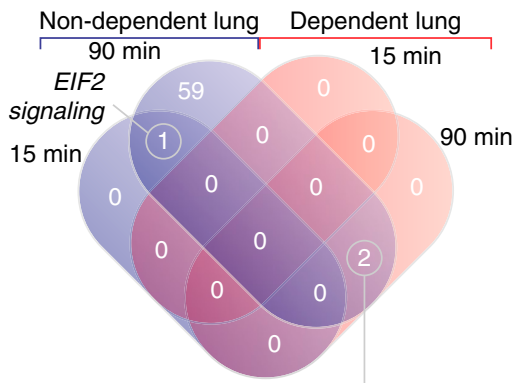

Mitochondrial dysfunction Oxidative phosphorylation

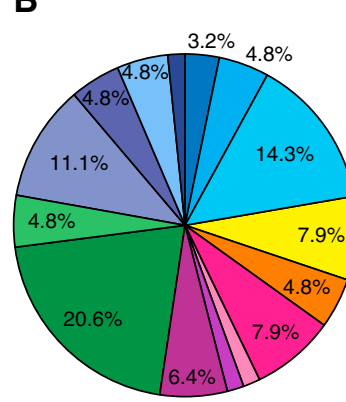

$\square$ Apoptosis (2)

$\square$ Cell cycle regulation (3)

$\square$ Cellular growth, proliferation, and development (9)

$\square$ Cellular immune response (5)

$\square$ Cellular stress and injury (3)

$\square$ Cytokine signaling (5)

$\square$ Disease-specific pathways (1)

$\square$ Generation of precursor

metabolites and energy (1)

$\square$ Growth factor signaling (4)

Intracellular and second messenger signaling (13)

$\square$ Neurotransmitters and nervous system signaling (3)

$\square$ Nuclear receptor signaling (7)

$\square$ Organismal growth and development (3)

$\square$ Pathogen-influenced

signaling (3)

$\square$ Xenobiotic metabolism (1)

\section{C}
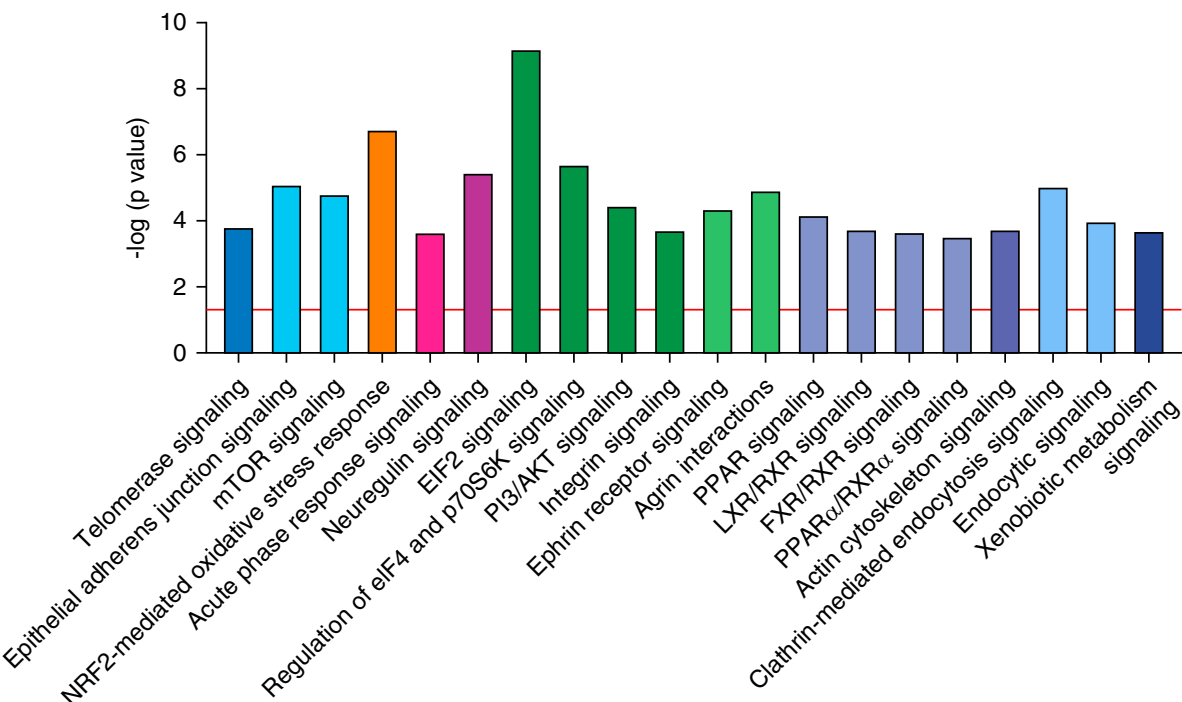

Figure 5. IPA identification of enriched canonical pathways. The threshold for identification of significant enrichments was 1.5 - $\log (P$ value) or greater and three or more proteins associated with the pathway. (A) Overlap of canonical pathway enrichments in nondependent and dependent lung after 15 or 90 minutes of ventilation. (B) Proportion of canonical pathways identified in 90-minute, nondependent lung tissue assigned to specific category descriptors by IPA. (C) Top 20 canonical pathways identified by IPA in 90-minute, nondependent lung tissue with the colored bars depicting the specific category descriptors. IPA identified enrichments based on their Fisher exact test $P$ value $(P<0.001$ all analysis $)$. EIF2 = eukaryotic initiation factor 2; FXR/RXR = farnesoid $X$ receptor/retinoid $X$ receptor; $L X R / R X R=$ liver $X$ receptor/retinoid $X$ receptor; $m$ TOR $=$ mammalian target of rapamycin; $p 70 S 6 K=P 70$ S6 kinase; $\mathrm{PPAR}=$ peroxisome proliferator-activated receptor; $\mathrm{PPAR} \alpha / \mathrm{RXR} \alpha=$ peroxisome proliferator-activated receptor $\alpha /$ retinoid $X$ receptor $\alpha$.

and interaction" were associated with a diverse range of cell types, including immune cells, blood cells, endothelial cells, epithelial cells, fibroblasts, neuroepithelial cells, blood platelets, connective tissue, neurons, and fibronectin matrix (Figure 6E). Within the functional category of "cell death," epithelial cell associations were identified in all three subcategories (apoptosis, cell death, and necrosis), with apoptosis also associated with immune cells, blood cells, neurons, and blood platelets (Figure 6F). Among "cellular growth and proliferation enrichments," fibroblasts were associated with the subcategories elastogenesis and proliferation, epithelial cells with development and proliferation, and immune cells with induction and proliferation (Figure 6G).

\section{Discussion}

VILI development within the preterm lung is mediated by a complicated, interconnected array of physiological insults, including mechanical traumas (stretch, shear stress) and increased oxygen exposure (oxidative stress), processes that are exacerbated by ventilation inhomogeneity (14). The complex array of injury-specific biomediators underlying the regional VILI response, and the timing of their expression, has not been comprehensively investigated. Using Orbitrap-MS and IPA, we were able to map the proteins and pathways that underlie VILI initiation and continuation in nondependent and gravity-dependent lung. Regional and temporal alterations in protein expression were highly varied, and included: 1) the temporal amplification within the nondependent lung of a single pathway (EIF2 signaling); 2) ventilationand aeration-associated alterations; 3 ) functionally specific alterations of oxidative phosphorylation/mitochondrial dysfunction pathway proteins in nondependent and dependent lung; and 4) alterations in vascular endothelial growth factor-, IL-6-, and RXRbased signaling pathways.

The established VILI paradigm suggests that lung injury begins with a few inappropriately applied inflations (2) with injury, then perpetuated with subsequent breaths (5). Our study of known injury markers, such as numbers of detached epithelial cells (both lung regions), the number of apoptotic cells, as well as EGR1 gene expression (nondependent lung only) was consistent with this paradigm. At the proteome level, EIF2 signaling in the nondependent lung was uniquely identified as being perpetuated and exacerbated with duration of ventilation. EIF2 signaling integrates both global and specific mRNA translation. However, after exposure to environmental stress, EIF2 signaling shifts from protein synthesis to the translation of stress-related mRNA transcripts involved in metabolism, the redox state of the cells, and apoptosis (15). Similarly, we observed that in the nondependent lung, environmental stress provided by 15 minutes of ventilation led to increased abundance of proteins related to global mRNA translation (EIF1AX, RPLP2, and RPL37A), whereas further ventilation for 90 minutes increased the diversity of EIF2 signaling to include 
A
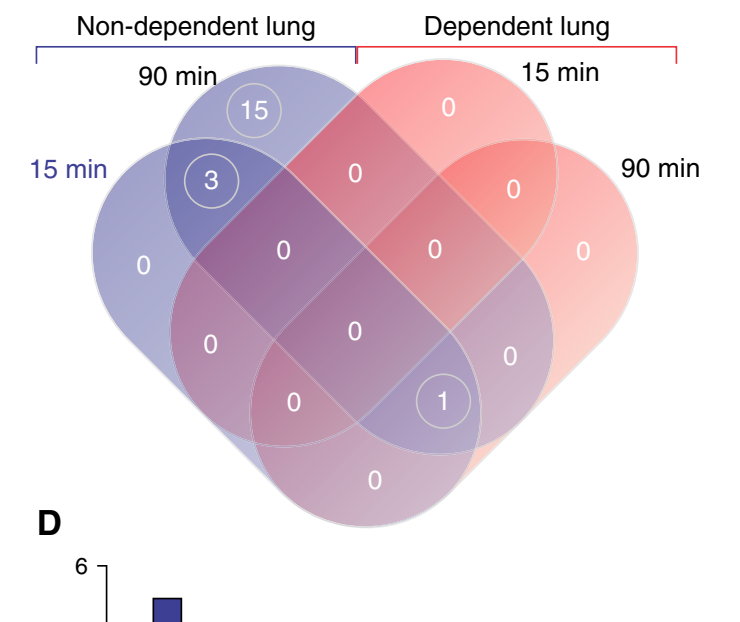

B

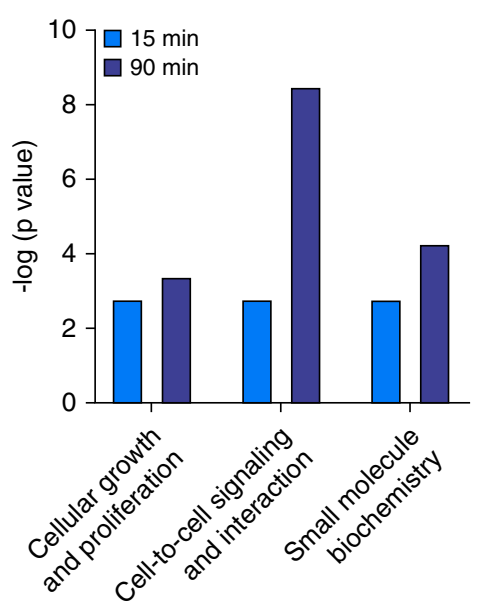

C

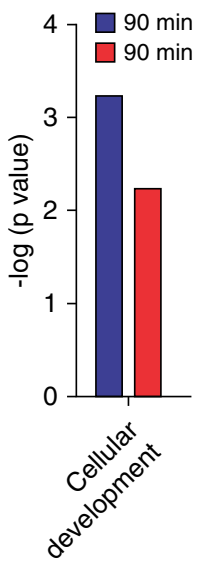

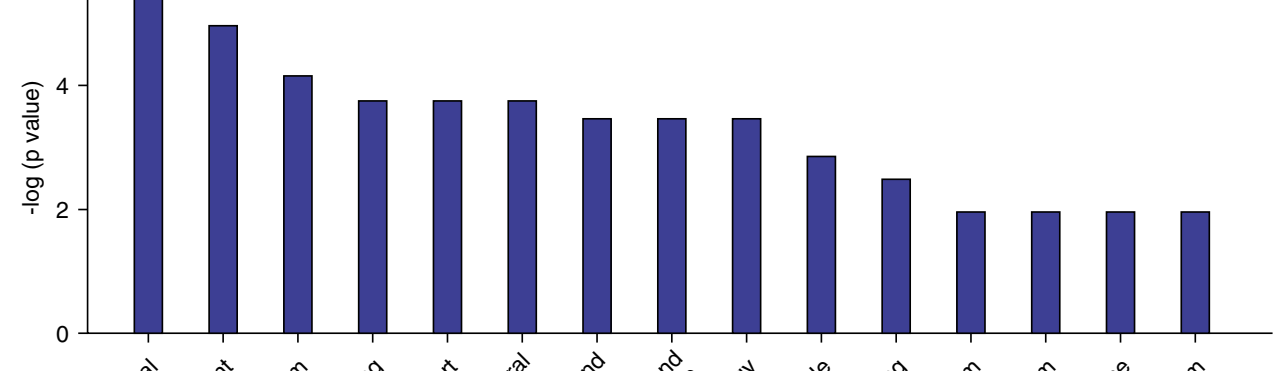

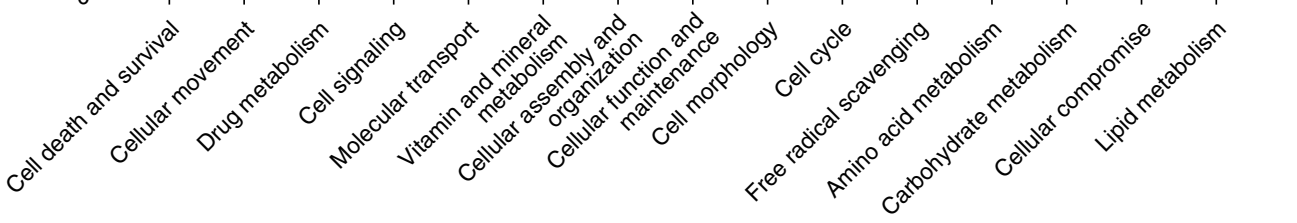

E

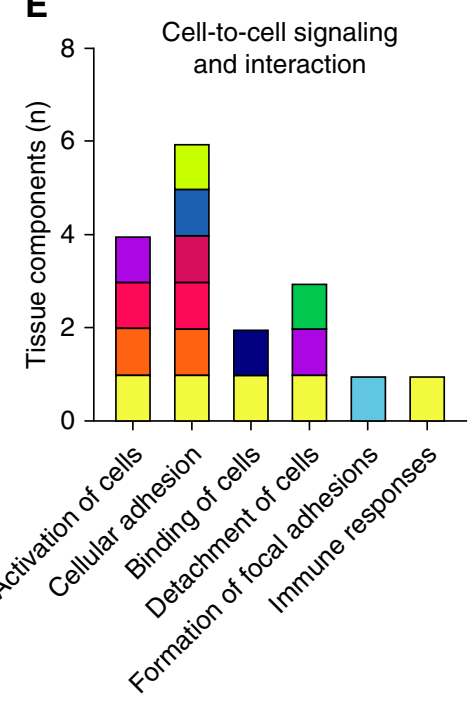

F

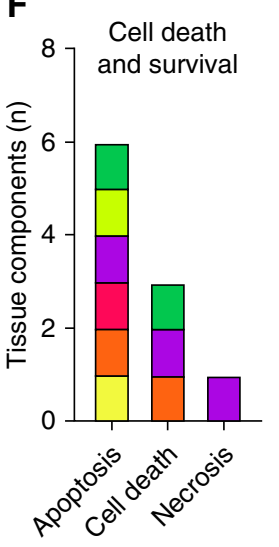

G

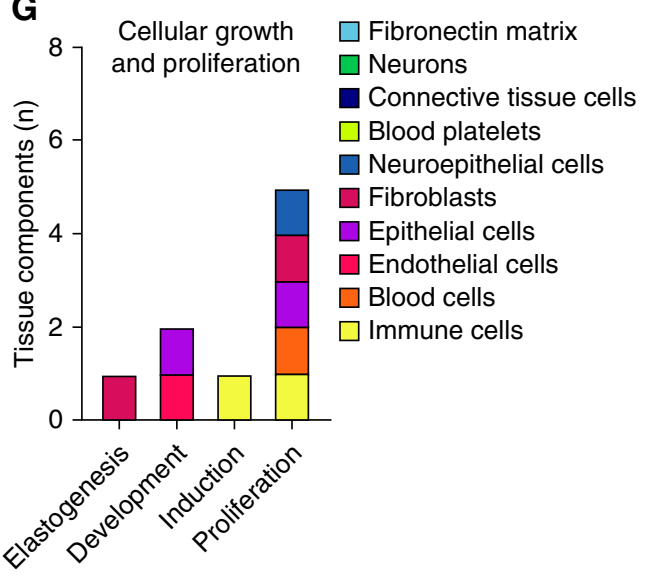

Figure 6. IPA identification of enriched molecular and cellular functions. The threshold for identification of significant enrichments was $1.5-\log (P$ value) or greater and three or more proteins associated with the pathway. (A) Overlap of functional molecular and cellular enrichments in nondependent and dependent lung after 15 or 90 minutes of ventilation. (B) Enrichments common to the nondependent lung. (C) Enrichments identified at 90 minutes of ventilation in both nondependent and dependent lung tissue. (D) Enrichments unique to nondependent lung tissue at 90 minutes of ventilation. IPA identified enrichments based on their Fisher exact test $P$ value $(P<0.001$, all analysis). Stacked bar graphs depict association of specific cell types within the enriched cellular and molecular function categories of $(E)$ cell-to-cell signaling and interaction, $(F)$ cell death, and survival and $(G)$ cellular growth and proliferation using the proteome of nondependent tissue exposed to 90 minutes of ventilation. 
both global translation proteins (RPLP1, RPLP2, RPS12, FAU, RPL19, RPS25) and specific mRNA translation proteins associated with proliferation and cell growth (KRAS, RPS6, RPS19), growth inhibition (RPL23A), cell migration (ACTC1, RPSA, ACTB), and angiogenesis (RRAS). Protein synthesis, performed by the ribosome, is the core of cellular life (16). Until recently, the structure of the ribosomal unit was considered largely invariant. However, recent studies have begun to uncover the impact of ribosomal composition on ribosomal function and the physiological state of the cell (16). The diversity of alterations identified in this study likely reflect the need for the respiratory cell population to rapidly alter the ribosomal proteome from a stable stoichiometry to increased translation of repair proteins in the face of continuing ventilation-initiated damage.

Imbalances in regional lung ventilation, with early relative overdistension of nondependent lung regions (17-19) and less aeration within gravitydependent regions $(19,20)$ are increasingly being linked with VILI development. In the current study, morphological assessments failed to confirm regional evidence of either histological volutrauma (via alveolar size measurements) or atelectasis (via variance in alveolar size), which may reflect histological-specific distortions in lung volume due to subjection of the lung to pressure curve measurements before fixation. However, preferential ventilation toward the nondependent lung was detected via EIT (functional imaging), and was associated with increased apoptosis and injury gene expression. Proteome alterations were similarly dominant within the nondependent lung, with $80 \%$ of differential proteins altered only in the nondependent lung, and $95 \%$ of canonical pathways and $78 \%$ of cellular and molecular functions uniquely enriched in nondependent lung ventilated for 90 minutes. Our results mirror gene array studies in which $81 \%$ of genes in nondependent lung tissues are differentially expressed in response to ventilation (21), and suggest that decreased alteration of the dependent lung proteome may reflect lack of ventilation rather than atelectasis or injury. In contrast, over-distension of the airways within the nondependent lung has previously been shown to result in direct tissue injury (17). However, concurrent atelectasis within the gravity-dependent lung may also injure distal, nonatelectatic airways (22). Although we were unable to elucidate the relative importance of volutrauma versus atelectotrauma in mediating VILI development, it is likely that both contributed to the magnitude of biotrauma response observed in nondependent lung tissue.

This study highlights both the clear distinctions and subtle nuances of the regional lung injury response to $\mathrm{PPV}$. For example, although the oxidative phosphorylation/mitochondrial dysfunction pathways were implicated in both nondependent and gravity-dependent lung, deeper investigation revealed clear region-specific mitochondrial alterations. There was an increase in the expression of respiratory chain complex IV (cytochrome $c$ oxidase) proteins in the nondependent lung, and decreased expression of respiratory chain complex III and V proteins in the gravity-dependent lung. We postulate that this mitochondrial response may reflect the different ventilation-associated physiological insults encountered within the nondependent and dependent lung exposed to mechanical stretch and oxidative stress, respectively. Cyclic mechanical stretch, including that which occurs during ventilation, has previously been shown to induce cell membrane stress failure, resulting in cell death and apoptosis of alveolar epithelial cells $(23,24)$ via the mitochondrial-initiated intrinsic pathway (25), with ventilated infants exhibiting increased lung expression of cleaved caspase-3 (26). In this study, preferential ventilation of the nondependent lung (as demonstrated by EIT) was accompanied by nondependent lung-specific increases in: gene expression of the stretch injury marker, IL-8, the number of cleaved caspase-3-positive apoptotic cells, and the protein expression of intrinsic apoptosis pathway mediators (COX5A, COX5B, COX6A1, and COX6B1). In contrast, the reduction of chain III and V proteins (UQCRC2, ATP50, ATP5I) in the gravity-dependent lung may indicate a hyperoxia-mediated decrease in ATP generation and energy supply, such as observed in the hyperoxia-treated newborn mouse model (27). Alternatively, these changes may reflect the oxidative mitochondrial DNA damage reported in ventilated preterm infants (28).

A major strength of this study was the use of proteomics, which allowed for the unbiased global identification of proteins and signaling pathways. Mirroring a previous gene array study of the ventilated rat lung (29), by not limiting our focus to previously studied injury mediators, we were able to develop a broader understanding of the cellular diversity driving the biotrauma response within the nondependent lung. Previous targeted studies of the biotrauma response have predominantly focused on inflammatory mediators; however, antiinflammation therapies have failed to inhibit lung injury (30). Similarly, our functional analysis of the differential protein set obtained from 90-minute nondependent lung suggested immune cell involvement in cellular functions, such as cell-to-cell signaling, cell death and survival, and proliferation. However, in line with our previous observations from the plasma proteome, functional analysis also suggested involvement of blood cells, blood platelets, and the fibronectin matrix (31), as well as proteins related to endothelial cell, epithelial cell, fibroblast, and neuronal function. Furthermore, our proteomic analysis not only confirmed known neonatal lung injury pathways, such as the extensively studied vascular endothelial growth factor $(32,33)$ and IL-6 (34-36) signaling pathways, but also identified an entirely novel association with three closely related RXR-mediated nuclear receptor families: LXR/RXR, FXR/RXR, and PPAR $\alpha / R X R \alpha$. Each of the nuclear receptors forms a heterodimer with RXR, and can be activated with agonists against either LXR/FXR/PPAR $\alpha$ or RXR during oxidative stress $(37,38)$ or under conditions of energy deprivation (39), resulting in activation of target genes involved in lipogenesis and inflammation. Central to disturbances in LXR, FXR, and PPAR $\alpha$ signaling pathways was a twofold decrease in FASN protein abundance in the nondependent lung. FASN is transcriptionally regulated by LXR (40), FXR (41), and retinol A (42). Functionally, decreased FASN expression is associated with inhibition of proliferation (43), providing a potential explanation for the regionally specific proliferation response observed in the 
current study. Furthermore, our results, when considered with recent studies of rodent model of respiratory disease, provide novel evidence for the consideration of LXR agonists as potential therapeutic candidates for the prevention and/or treatment of preterm VILI. In rodent models, LXR agonist treatment has been shown to provide protection against lung injury via decreased production of ROS (37), attenuation of the inflammatory response (44-46), and promotion of pulmonary remodeling (47). These are pathological features reminiscent of preterm lung injury.

\section{Limitations}

There are a number of limitations of this study. In our recreation of the clinical scenario experienced by the preterm human, PPV was supplemented with blended oxygen, and thus we were unable to fully distinguish between the effects of mechanotrauma and those of oxidative stress. Similarly, although ventilation heterogeneity was identified via EIT, our inability to differentiate volutrauma versus atelectasis states in regional, histological samples prevents us from assigning observed protein alterations to a specific mechanotrauma. We concede that, although the placental support and neonatal ventilation lambs were largely comparable with regard to the pressure and volume effects within the lung, the provision of continuing placental support in the 15minute ventilation groups may have limited the systemic effects of oxygen on the lungs and other tissues. In line with current respiratory support management practices, betamethasone was administered in all mothers, and this may have influenced proteome expression. However, among the differential proteins identified, only the expression of ABCC4 (48) and LGALS1 (49) has been previously associated with betamethasone administration. Although we sampled comparable regions between animals for each type of analysis, the patterns of injury we have reported may differ if alternative sample sites are used. Guo and colleagues (50) recently observed gene expression changes in a range of pulmonary cell types in response to initiation of respiration at birth in mice using single-cell RNA analysis. Our use of whole-tissue samples did not allow for attribution of observed protein changes to a specific pulmonary cell compartment. However, a diverse range of cell types was implicated in the enriched function analysis, suggesting that single-cell proteomic studies are warranted. Finally, our lambs were anesthetized and supported via a cuffed endotracheal tube without any spontaneous respiratory effort, inconsistent with clinical practice. Recent studies have demonstrated that: 1) dynamic changes in gene expression occur in response to initiation of normal breathing at birth (50); and 2) greater injury within the dependent lung during spontaneous effort in experimental models of acute respiratory distress syndrome (51), suggesting that it is likely that noninvasive respiratory support and/or spontaneous breathing may lead to different patterns of protein expression.

\section{Conclusions}

The cumulative findings of our study imply that management of the first few breaths is essential to modulating the injury process, and that an understanding of regional VILI pathogenesis is required for the development of improved lungprotective ventilation strategies. Complex injury pathways were initiated within the preterm lung after 15 minutes of ventilation and amplified by continuing ventilation. Injury development is region specific with greater alterations within the proteome of nondependent lung. These regional proteomic datasets provide the first maps of the regionally specific protein alterations, which underlie VILI development in the preterm lung, thereby defining pathways and functions that can be targeted for therapeutic intervention aimed at the prevention or resolution of VILI.

Author disclosures are available with the text of this article at www.atsjournals.org.

\begin{abstract}
Acknowledgment: The authors thank the following employees of the Murdoch Children's Research Institute: Magdy Sourial for expert technical assistance with the animals, Sarah White and Rebecca Sutton for assistance in preparation of the ewes, Dr. Anushi Rajapaksa for data preparation, and Georgie Dowse for assistance in electrical impedance tomography analysis.
\end{abstract}

\section{References}

1. Jobe AH, Hillman N, Polglase G, Kramer BW, Kallapur S, Pillow J. Injury and inflammation from resuscitation of the preterm infant. Neonatology 2008;94:190-196.

2. Björklund LJ, Ingimarsson J, Curstedt T, John J, Robertson B, Werner O, et al. Manual ventilation with a few large breaths at birth compromises the therapeutic effect of subsequent surfactant replacement in immature lambs. Pediatr Res 1997;42:348-355.

3. Tingay DG, Pereira-Fantini PM, Oakley R, McCall KE, Perkins EJ, Miedema $\mathrm{M}$, et al. Gradual aeration at birth is more lung protective than a sustained inflation in preterm lambs. Am J Respir Crit Care Med [online ahead of print] 7 Feb 2019; DOI: 10.1164/rccm.201807$13970 \mathrm{OC}$.

4. Tingay DG, Rajapaksa A, McCall K, Zonneveld CE, Black D, Perkins E, et al. The interrelationship of recruitment maneuver at birth, antenatal steroids, and exogenous surfactant on compliance and oxygenation in preterm lambs. Pediatr Res 2016;79:916-921.

5. Hillman NH, Moss TJ, Kallapur SG, Bachurski C, Pillow JJ, Polglase GR, et al. Brief, large tidal volume ventilation initiates lung injury and a systemic response in fetal sheep. Am J Respir Crit Care Med 2007; 176:575-581.
6. Tingay DG, Polglase GR, Bhatia R, Berry CA, Kopotic RJ, Kopotic CP, et al. Pressure-limited sustained inflation vs. gradual tidal inflations for resuscitation in preterm lambs. J Appl Physiol (1985) 2015;118: 890-897.

7. Tingay DG, Rajapaksa A, Zonneveld CE, Black D, Perkins EJ, Adler A, et al. Spatiotemporal aeration and lung injury patterns are influenced by the first inflation strategy at birth. Am J Respir Cell Mol Biol 2016; 54:263-272.

8. Yen S, Preissner M, Bennett E, Dubsky S, Carnibella R, O'Toole R, et al. The link between regional tidal stretch and lung injury during mechanical ventilation. Am J Respir Cell Mol Biol [online ahead of print] 14 Nov 2018; DOI: 10.1165/rcmb.2018-01430C.

9. Cressoni M, Cadringher P, Chiurazzi C, Amini M, Gallazzi E, Marino A, et al. Lung inhomogeneity in patients with acute respiratory distress syndrome. Am J Respir Crit Care Med 2014;189:149-158.

10. Hillman NH, Nitsos I, Berry C, Pillow JJ, Kallapur SG, Jobe AH. Positive end-expiratory pressure and surfactant decrease lung injury during initiation of ventilation in fetal sheep. Am J Physiol Lung Cell Mol Physiol 2011;301:L712-L720.

11. McCall KE, Waldmann AD, Pereira-Fantini P, Oakley R, Miedema M, Perkins EJ, et al. Time to lung aeration during a sustained inflation at birth is influenced by gestation in lambs. Pediatr Res 2017;82:712-720. 
12. Livak KJ, Schmittgen TD. Analysis of relative gene expression data using real-time quantitative PCR and the 2(-delta delta $\mathrm{C}(\mathrm{T}))$ method. Methods 2001;25:402-408.

13. Pereira-Fantini PM, Rajapaksa AE, Oakley R, Tingay DG. Selection of reference genes for gene expression studies related to lung injury in a preterm lamb model. Sci Rep 2016;6:26476.

14. Armstrong RK, Carlisle HR, Davis PG, Schibler A, Tingay DG. Distribution of tidal ventilation during volume-targeted ventilation is variable and influenced by age in the preterm lung. Intensive Care Med 2011;37:839-846.

15. Wek RC, Jiang HY, Anthony TG. Coping with stress: elF2 kinases and translational control. Biochem Soc Trans 2006;34:7-11.

16. Guimaraes JC, Zavolan M. Patterns of ribosomal protein expression specify normal and malignant human cells. Genome Biol 2016;17:236.

17. Tingay DG, Rajapaksa A, Zannin E, Pereira-Fantini PM, Dellaca RL, Perkins EJ, et al. Effectiveness of individualized lung recruitment strategies at birth: an experimental study in preterm lambs. Am J Physiol Lung Cell Mol Physiol 2017;312:L32-L41.

18. Tingay DG, Lavizzari A, Zonneveld CE, Rajapaksa A, Zannin E, Perkins E, et al. An individualized approach to sustained inflation duration at birth improves outcomes in newborn preterm lambs. Am J Physiol Lung Cell Mol Physiol 2015;309:L1138-L1149.

19. Yoshida T, Amato MBP, Grieco DL, Chen L, Lima CAS, Roldan R, et al. Esophageal manometry and regional transpulmonary pressure in lung injury. Am J Respir Crit Care Med 2018;197: 1018-1026.

20. Stankiewicz-Rudnicki M, Gaszyński T, Gaszyński W. Assessment of regional ventilation in acute respiratory distress syndrome by electrical impedance tomography. Anaesthesiol Intensive Ther 2015; 47:77-81.

21. Simon BA, Easley RB, Grigoryev DN, Ma SF, Ye SQ, Lavoie T, et al. Microarray analysis of regional cellular responses to local mechanical stress in acute lung injury. Am J Physiol Lung Cell Mol Physiol 2006;291:L851-L861.

22. Tsuchida S, Engelberts D, Peltekova V, Hopkins N, Frndova H, Babyn $\mathrm{P}$, et al. Atelectasis causes alveolar injury in nonatelectatic lung regions. Am J Respir Crit Care Med 2006;174:279-289.

23. Kroon AA, Delriccio V, Tseu I, Kavanagh BP, Post M. Mechanical ventilation-induced apoptosis in newborn rat lung is mediated via FasL/Fas pathway. Am J Physiol Lung Cell Mol Physiol 2013;305: L795-L804.

24. Hammerschmidt S, Kuhn H, Grasenack T, Gessner C, Wirtz H. Apoptosis and necrosis induced by cyclic mechanical stretching in alveolar type II cells. Am J Respir Cell Mol Biol 2004;30:396-402.

25. Kuhn H, Nieuwenhuijsen $\mathrm{H}$, Karthe B, Wirtz H. Stretch-induced apoptosis in rat alveolar epithelial cells is mediated by the intrinsic mitochondrial pathway. Exp Lung Res 2017;43:49-56.

26. May M, Ströbel P, Preisshofen T, Seidenspinner S, Marx A, Speer CP. Apoptosis and proliferation in lungs of ventilated and oxygen-treated preterm infants. Eur Respir J 2004;23:113-121.

27. Ratner V, Starkov A, Matsiukevich D, Polin RA, Ten VS. Mitochondrial dysfunction contributes to alveolar developmental arrest in hyperoxia-exposed mice. Am J Respir Cell Mol Biol 2009;40:511518.

28. Maniscalco WM, Watkins RH, Roper JM, Staversky R, O'Reilly MA Hyperoxic ventilated premature baboons have increased p53, oxidant DNA damage and decreased VEGF expression. Pediatr Res 2005;58:549-556.

29. Copland IB, Kavanagh BP, Engelberts D, McKerlie C, Belik J, Post M. Early changes in lung gene expression due to high tidal volume. $A m$ J Respir Crit Care Med 2003;168:1051-1059.

30. Hillman NH, Kallapur SG, Pillow JJ, Nitsos I, Polglase GR, Ikegami M, et al. Inhibitors of inflammation and endogenous surfactant pool size as modulators of lung injury with initiation of ventilation in preterm sheep. Respir Res 2010;11:151.

31. Pereira-Fantini PM, Byars SG, McCall KE, Perkins EJ, Oakley RB, Dellacà RL, et al. Plasma proteomics reveals gestational agespecific responses to mechanical ventilation and identifies the mechanistic pathways that initiate preterm lung injury. Sci Rep 2018; 8:12616.
32. Oak P, Hilgendorff A. The BPD trio? Interaction of dysregulated PDGF, VEGF, and TGF signaling in neonatal chronic lung disease. Mol Cell Pediatr 2017;4:11

33. De Paepe ME, Greco D, Mao Q. Angiogenesis-related gene expression profiling in ventilated preterm human lungs. Exp Lung Res 2010;36: 399-410.

34. Hsiao CC, Chang JC, Tsao LY, Yang RC, Chen HN, Lee CH, et al. Correlates of elevated interleukin-6 and 8-hydroxy-2' deoxyguanosine levels in tracheal aspirates from very low birth weight infants who develop bronchopulmonary dysplasia. Pediatr Neonatol 2017;58:63-69.

35. Iwatani S, Mizobuchi M, Tanaka S, Fujioka K, Wada K, Sakai H, et al. Increased levels of interleukin-6 in tracheal aspirate fluid are indicative of fetal inflammation in ventilated extremely low gestational age newborns. Kobe J Med Sci 2014;60:E19-E24.

36. Tullus K, Noack GW, Burman LG, Nilsson R, Wretlind B, Brauner A. Elevated cytokine levels in tracheobronchial aspirate fluids from ventilator treated neonates with bronchopulmonary dysplasia. Eur $J$ Pediatr 1996;155:112-116.

37. Gong H, He J, Lee JH, Mallick E, Gao X, Li S, et al. Activation of the liver $\mathrm{X}$ receptor prevents lipopolysaccharide-induced lung injury. $\mathrm{J}$ Biol Chem 2009;284:30113-30121.

38. Lívero FA, Stolf AM, Dreifuss AA, Bastos-Pereira AL, Chicorski R, de Oliveira LG, et al. The FXR agonist 6ECDCA reduces hepatic steatosis and oxidative stress induced by ethanol and low-protein diet in mice. Chem Biol Interact 2014;217:19-27.

39. Kersten S, Seydoux J, Peters JM, Gonzalez FJ, Desvergne B, Wahli W. Peroxisome proliferator-activated receptor alpha mediates the adaptive response to fasting. $J$ Clin Invest 1999;103: 1489-1498.

40. Shi HB, Zhang CH, Xu ZA, Xu XF, Lv ZB, Luo J, et al. Nuclear receptor subfamily 1 group $\mathrm{H}$ member 2 (LXRB) is the predominant liver $X$ receptor subtype regulating transcription of 2 major lipogenic genes in goat primary mammary epithelial cells. J Dairy Sci 2017;100:6743-6752.

41. Shen LL, Liu H, Peng J, Gan L, Lu L, Zhang Q, et al. Effects of farnesoid $X$ receptor on the expression of the fatty acid synthetase and hepatic lipase. Mol Biol Rep 2011;38:553-559.

42. Chailley-Heu B, Chelly N, Lelièvre-Pégorier M, Barlier-Mur AM, MerletBénichou C, Bourbon JR. Mild vitamin A deficiency delays fetal lung maturation in the rat. Am J Respir Cell Mol Biol 1999;21: 89-96.

43. Lu T, Schubert C, Cummings MD, Bignan G, Connolly PJ, Smans K, et al. Design and synthesis of a series of bioavailable fatty acid synthase (FASN) KR domain inhibitors for cancer therapy. Bioorg Med Chem Lett 2018;28:2159-2164.

44. Shi Y, Chen Q, Yan H, Gu W. The effect of a liver-X-receptor ligand on bleomycin induced pulmonary fibrosis in mice. Int Immunopharmacol 2016;41:116-121.

45. Zhao Z, Xu D, Li S, He B, Huang Y, Xu M, et al. Activation of liver X receptor attenuates oleic acid-induced acute respiratory distress syndrome. Am J Pathol 2016;186:2614-2622.

46. Crisafulli C, Mazzon E, Paterniti I, Galuppo M, Bramanti P, Cuzzocrea S. Effects of liver $\mathrm{X}$ receptor agonist treatment on signal transduction pathways in acute lung inflammation. Respir Res 2010;11:19.

47. Shi Y, Xu X, Tan Y, Mao S, Fang S, Gu W. A liver-X-receptor ligand, T0901317, attenuates IgE production and airway remodeling in chronic asthma model of mice. PLoS One 2014;9:e92668.

48. Neuhaus W, Schlundt M, Fehrholz M, Ehrke A, Kunzmann S, Liebner $\mathrm{S}$, et al. Multiple antenatal dexamethasone treatment alters brain vessel differentiation in newborn mouse pups. PLoS One 2015;10: e0136221.

49. Sena AA, Provazzi PJ, Fernandes AM, Cury PM, Rahal P, Oliani SM. Spatial expression of two anti-inflammatory mediators, annexin 1 and galectin-1, in nasal polyposis. Clin Exp Allergy 2006;36: 1260-1267.

50. Guo M, Du Y, Gokey JJ, Ray S, Bell SM, Adam M, et al. Single cell RNA analysis identifies cellular heterogeneity and adaptive responses of the lung at birth. Nat Commun 2019;10:37.

51. Morais CCA, Koyama Y, Yoshida T, Plens GM, Gomes S, Lima CAS, et al. High positive end-expiratory pressure renders spontaneous effort noninjurious. Am J Respir Crit Care Med 2018;197:1285-1296. 